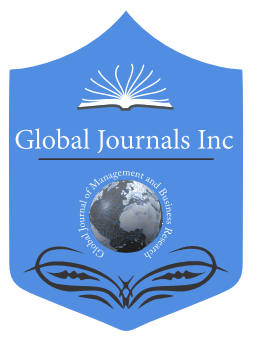

Global JOURNAL of MANAGEMENT AND BUSINESS RESEARCH: A ADMINISTRATION AND MANAGEMENT

Volume 20 Issue 14 Version 1.0 Year 2020

Type: Double Blind Peer Reviewed International Research Journal

\title{
No Room for Micromanagement in the 21st Century
}

\section{By Michael Castro, D.B.A.}

University Professor \& Entrepreneur

Abstract- The purpose of this paper was to provide all individuals within leadership roles with an enriched comprehension about micromanagement and the negative effects it possesses on subordinates. This objective was fulfilled by the researcher conducting investigations on numerous articles and studies conducted by other specialist in the field of supervision and management. The researcher also incorporated past experiences that were exhibited in past organizations pertaining to staff being micromanaged by different personnel in leadership roles.

Keywords: micromanagement, negative effects, millennials.

GJMBR-A Classification: JEL Code: M10

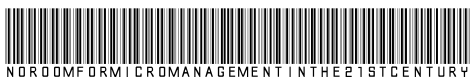

Strictly as per the compliance and regulations of:

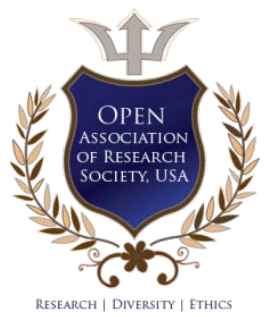

(C) 2020. Michael Castro, D.B.A. This is a research/review paper, distributed under the terms of the Creative Commons Attribution-Noncommercial 3.0 Unported License http://creativecommons.org/licenses/by-nc/3.0/), permitting all non-commercial use, distribution, and reproduction in any medium, provided the original work is properly cited. 


\title{
No Room for Micromanagement in the 21st Century
}

\author{
Michael Castro, D.B.A.
}

Abstract The purpose of this paper was to provide all individuals within leadership roles with an enriched comprehension about micromanagement and the negative effects it possesses on subordinates. This objective was fulfilled by the researcher conducting investigations on numerous articles and studies conducted by other specialist in the field of supervision and management. The researcher also incorporated past experiences that were exhibited in past organizations pertaining to staff being micromanaged by different personnel in leadership roles.

Keywords: micromanagement, negative effects, millennials.

\section{IndicATORS That AN INDIVIDUAL IS A Micromanager}

ndividuals that micromanage their staff do not realize that they are utilizing this particular approach. These individuals primarily focused on attention to detail, verifying that the day-to-day tasks are being completed accordingly. However, they tend to go over board while supervising and managing these employees. The following are some different signals that indicated if an individual is micromanaging their staff as per Wilkins (2014):

- The superior is not satisfied with the deliverables of the staff.

- The superior feels frustrated most of the time for the reason that they would have utilized a different approach to fulfill the task.

- The superior mainly focuses on details and constantly looking for corrections.

- As a routine, the supervisor must know where the staff is located and what tasks are they working on.

- $\quad$ The superior requests frequent updates on all tasks.

- Any correspondences (emails) between the staff, requires them to include the superior within them.

\section{il. Millennials are the new Working Force in the 21 ${ }^{\text {st }}$ Century}

Millennials or Generation Y occupy about 36\% of the workforce and is constantly growing. It is estimated that by 2020, Millennials will occupy about $46 \%-50 \%$ of the workforce compared to the other older generations: (Generation X, Baby Boomers) as per Jackson (2016). Millennials are made up of roughly 80

Author: University Professor \& Entrepreneur 136 SW $11^{\text {TH }}$ AVE MIAMI, FL 33174. e-mail: Michae/castro333@gmail.com million young adults that were born between 1976 and 2001 according to the U.S Bureau of Labor Statistics. Millennials grew up around technology and have a different mindset compared to their predecessors (Generation X, Baby Boomers). They are considered to be technological-savvy and multitasking is a norm for these young adults.

Millennials pride themselves in constantly leaning, personal development and overall growth. This group is categorized as independent learners. When population is micromanaged, it results in loss of productivity and disengagement (Bielaszka-DuVernay (2007); Romero, 2012). When micromanaging takes place, this group becomes discouraged and begin to start losing interest in their job. This is due to the fact that they feel that they have no ownership within the process of the work being assigned to them and their superior is the one that does (Romero, 2012, p.8).

\section{ili. Effective Approaches on Managing Millennials}

Tulgan (2009) reported that if managed correctly, millennials will be the most productive workforce the U.S. has ever had (p. 4). The following are different approaches that can be utilized by superiors when managing the millennial group.

\section{a) Creating a Desirable Working Environment}

In order to retain and keep employee moral high at the workplace, creating a desirable working environment is vital. Generation Y seeks a new working environment in contrast to their predecessors who accepted the archetypical working environment (Cahill \& Sedrak, 2012).

\section{b) Improving Recognition Programs}

Continuous feedback on performance are different techniques that the millennial group has adapted to in order to stay on track during changes within an organization. Suleman \& Nelson (2011) explained that providing feedback and praising serve as a reinforcement and a corrective mechanism tool.

\section{c) Assigning work that has a Purpose}

In order to obtain trust from this group, superiors should assign tasks that have significant meaning towards the organization. Millennials seek to complete tasks that have significant meaning in which 
contributes to the overall mission and vision of the organization (Hewlett, et al., 2009).

d) Incorporating Sophisticated Methods To

When a member of this group sends a message to their superior, they expect a response immediately after as per Cekada (2012). Most times, they value the rate of response rather than the accuracy behind it. Superiors should practice on their turnaround time when providing a response to this group. Utilizing other means of communication can also be beneficial such as instant messaging, blogging, texting, and emails (Cekada, 2012, p. 42).

\section{Conclusion}

Managing employees can be a difficult task at times however; it is the responsibility of that superior to understand which management style or styles will be most effective with the staff. Millennials are a group that have opposite views and were raised differently from past generations. Individuals in leadership roles need to focus on understanding how to properly deal with these differences, in order to support the organizations mission/vision as well as keeping these employees satisfied. As a result, managers will become aware of the generational differences within the workplace and understand how to adjust management techniques in order to achieve positive results with this generation of employees.

\section{References Références Referencias}

1. Balda, J. B., \& Mora, F. (2011). Adapting leadership theory and practice for the networked, Millennial generation, Journal of Leadership Studies, 5 (3), 13-24.

2. Bielaszka-Du Vernay, C. (2007). Micromanage at your peril. Harvard Management Update, 12(2), 3

3. Brack, J., \& Kelly, K. (2012). Maximizing Millennials in the Workplace. North Carolina: UNC KenanFlagler Business School. Retrieved from https://www.kenan-flagler.unc.edu/executive-develo pment/custom-programs/ /media/files/documents /executive-development/maximizing-millennials-inthe-workplace.pdf

4. Cahill, T. F., \& Sedrak, M. (2012). Leading Multigenerational Workforce: Strategies for Attracting and Retaining Millennials. Frontiers of Health Services Management, 29(1), 3-15.

5. Cekada, T. L. (2012). Training a multigenerational workforce. Professional Safety, 57(3), 40-44.

6. Hewlett, S. A., Sherbin, L., \& Sumberg, K. (2009). How Gen Y \& Boomers will reshape your agenda. Harvard Business Review, 87(7/8), 41-52.

7. Jackson, H. G. (2016, July 1). Three Principles of the 21st Century Workplace. SHRM Society for Human
Resource Management. Retrieved from https:// www.shrm.org/hr-today/news/hrmagazine/0716/pag es/three-principles-of-the-21st-centuryworkplace.a spx

8. Romero, E. J. (2012). Stop micromanaging: It isn't the same as attention to detail. Sales \& Service Excellence, 12(9), 8.

9. Suleman, R., \& Nelson, B. (2011). Motivating the Millennials: Tapping into the potential of the youngest generation. Leader to Leader, 2011(62), 39-44.

10. Wilkins, M. M. (2014). Signs That You're a Micromanager. In Harvard Business Review. Retrieved from https://hbr.org/2014/11/signs-thatyoure-a-micromanager 